\title{
Making the World More Sustainable: Enabling Localized Energy Generation and Distribution on Decentralized Smart Grid Systems
}

\author{
Harrison John Bhatti', Mike Danilovic ${ }^{1,2}$ \\ ${ }^{1}$ School of Business, Engineering and Science, Halmstad University, Halmstad, Sweden \\ ${ }^{2}$ Shanghai Dianji University, Shanghai, China \\ Email: harrisonjohn03@gmail.com,mike.da nilovic@hh.se
}

How to cite this paper: Bhatti, H.J. and Danilovic, M. (2018) Making the World More Sustainable: Enabling Localized Energy Generation and Distribution on Decentralized Smart Grid Systems. World Journal of Engineering and Technology, 6, 350-382.

https://doi.org/10.4236/wjet.2018.62022

Received: March 26, 2018

Accepted: May 12, 2018

Published: May 15, 2018

Copyright $\odot 2018$ by authors and Scientific Research Publishing Inc. This work is licensed under the Creative Commons Attribution International License (CC BY 4.0).

http://creativecommons.org/licenses/by/4.0/

(C) (i) Open Access

\begin{abstract}
Smart grid is an idea of upgradation of the traditional electric grid infrastructure. The efficiency of the existing electrical grid can be automated by integrating with innovative technical equipment such as: high-tech forecasting system, digital sensors, advanced two-way communication and two-way power flow systems. Smart grid establishes an interface between utility and consumer which helps to use energy, based on the preferences of price, eco-friendly and without technical system issues. It empowers the grid to be more secure, reliable and efficient. The peer-reviewed articles and published government reports have been reviewed, based on the analysis of technical characteristics of power generation systems, eco-friendly sources of power generations, cost reduction, functionality and design of traditional grid versus smart grid. Furthermore, the innovative technologies that enable the grid to integrate with decentralized power generation system efficiently have been considered. This paper claims that in this modern era, it is arduous for traditional grid to fulfill the rising demand of electricity, along with sustainable, eco-friendly and stable power supply, as it cannot be efficiently integrated with decentralized and localized power generation systems and renewable energy sources. The result of this paper shows that decentralized and localized power generation systems are located close to end-users which decrease the transmission and supply cost of electricity. Innovative technologies allow the decentralized and localized power generation systems to be integrated with renewable energy sources which help to reduce the cost of utility services and provide clean energy. Moreover, technological advancement played a decisive role in enabling the electrical system to be more efficient. Electrical reliability can be improved, greenhouse gas emissions can be reduced, renewable energy sources can efficiently be integrated, and rising demand for electricity can be
\end{abstract}


met by embedding advanced applications and technological equipment in the electrical grid.

\section{Keywords}

Smart Grid, Traditional Grid, Centralized Power Generation, Decentralized Power Generation, Innovative Technologies

\section{Introduction}

Nowadays, the world is facing critical challenges, such as: uninterrupted power supply, saving organic fuels, growing population, rising unemployment level and the improvement of living standards. Further challenges are the contribution of sustainable development in distant areas specifically in mountainous territories and desserts. One of the reasons is the depletion of fossil fuels which is a threatening call for the energy sector and drives them to explore alternative ways for energy sources. The energy sector is highly dependable on oil which is unsustainable and very limited in the world. The main reason of greenhouse gases is the burning of fossil fuels which is directly impacting on the climate change of the world [1]. The solution of all challenges is connected with the development of renewable energy system [2]. Furthermore, according to Bergmann et al. [3], numerous jobs could be created in village regions by developing and using the system of renewable energy.

One of the central factors of economic development in all countries is electricity. Always on demand for electric power generation is challenging both developing and developed countries. Continuous producing electricity gives immense pressure to the infrastructure of electrical energy. In developing countries, almost half of the population live in rural areas. For these regions, electricity delivery is very costly which local people cannot pay, and it causes social inequality and low living standard [4]. Bhattacharyya [5] gave an example of India, where more than $70 \%$ of the population live in village areas. Furthermore, in India over $40 \%$ of the total population do not have electricity. According to Kaundinya et al. [4], the triple growth of electricity delivery and the fivefold growth of electricity generation are required for satisfying electricity demand growth. Almost 3\% of global GDP should be invested per year for facing the electricity demand and generation challenge. Due to new employment, migration from rural areas to cities will decrease and reach a minimum level. Hiremath et al. [6] and Ravindranath et al. [7] stated that in village regions, one of the best, reliable and environmentally secure ways for satisfying electricity demand and making electricity less costly, is the implementation of renewable energy with decentralized generation. It is difficult for the centralized power generation system to fulfill the growing demand for electricity without burning fossil fuels and emitting greenhouse gases. The evolutionary concept of smart grid technologies is driven by these complex challenges [8]. According to Li et al. [9], the term "smart grid" is 
primarily considered as an electric grid which is capable of delivering electricity from points of generation to consumers in a smart and controlled way. Consumers can modify their purchasing patterns of electricity according to the need and demand based on the received information from smart grid. Xiang et al. [10] and [8] explain that compare to a traditional grid system; a smart grid is the combination of digitalized innovative communication devices, circuit breakers, and transformers which enhance safety, efficiency and operational performance of the grid. It is recommended to have a robust and highly reliable network connection which can support the interaction between application software and electrical services. Furthermore, Mohani et al. [11] describe that specialized processors, automated metering systems, sensors, communication systems and intelligent devices are required for the complete integration of smart grid. These energy management technologies help to save energy as well as exploiting the sources of renewable energy.

Hiremath et al. [12] stated that reliance on centralized power generation system causes high costs for electricity delivery and inflexibility. This system is using mainly fossil fuels for functioning, and huge capital is required for installing transmission and distribution grids in distant regions. Outflows of obnoxious gases create burning of fossil fuels, which are dangerous for local climate and health problems. Solving these challenges an alternative power generation and distribution systems are required. With comparison to centralized systems of energy, decentralized energy systems are using sustainable sources of energy, in conditions of grid presence or absence the systems run on lower scales, such as kilowatt scale.

Moreover, decentralized system of energy generations gives access to remote locations because power generation is matching with demand. Thus, implementing decentralized systems of energy could solve the problem with electricity delivery in village areas. The solution is fruitful because decentralized systems provide reliable and renewable energy delivery. According to Kaundinya et al. [4] in 2004 total share of a decentralized system of electricity generation reached to $7.2 \%$ by growing $0.2 \%$ from 2002 . Decentralized generation gives more potential for electricity generation. From the point of electric power generation, decentralized energy had rapid growth in the world by reaching 25\% in 2005 from $13 \%$ in 2001. Furthermore, the ratio of decentralized power generation system increased $11 \%$ within a year and reached up to $36 \%$ in 2006 [13]. Kim et al. [14] state that there is positive prognosis about the future growth of decentralized systems due to benefits, which it gives. According to calculations, global cost reduction from electricity generation could reach $\$ 2.7$ trillion by 2030 if decentralized systems are embraced [15].

According to the today's demand for electricity, the traditional grid is getting obsolete and is required to be re-engineered, redesigned and equipped with innovative and modern technologies. Smart technologies which can be embedded in the electrical network made the transformation process possible for electric grid into a smart grid. Reliability and energy security are the significant eco- 
nomic challenges of the $21^{\text {st }}$ century for the grid to integrate with renewable energy sources. The basic concept of smart grid is, the innovative technology can be integrated at all phases of grid actions and management. Implementation of digitalized and intelligent functions into the grid will increase the general efficiency of energy. Furthermore, this transformation of the grid would establish better interaction between consumer and grid [16]. Therefore, it is significant to explore the sustainable energy management system which can efficiently be integrated with renewable energy sources and decentralized power generation systems that support to reduce the usage of fossil fuels along with achieving the rising demand of electricity.

This paper is categorized into five main segments: such as renewable and non-renewable energy sources, power generation systems, traditional grid, technological development and smart grid.

\section{Purpose of the Study}

The purpose of this paper is to explore the state of the art of grid systems focusing on the evolution of innovative technologies which transform traditional grid into smart grid and enhances its performance. Moreover, the comparison between energy sources, power generation systems, traditional grid and smart grid systems have been executed based on their availability, efficiency, cost and operational performance to explore the proper distribution system of energy which can fulfill the rising demand of electricity and can provide clean energy in low price.

\section{Research Methodology}

In order to explore the transformation process of energy distribution system, a review on the "electricity" and "smart grid" literature was conducted. Data had been obtained from various databases, such as; IEEE, ACM digital library, Scopus, Web of Science, Science Direct and published government reports. The use of these databases allowed to achieve the comprehensive list of peer-reviewed articles and reports on smart grid and power generation sources. Three major steps had been taken to conduct the research: 1) identification and skimming 2) filtering and screening and 3) analysis of filtered data.

The first step is associated with identifying scientific articles and reports based on the topics of smart grid, renewable energy sources, centralized and decentralized systems of power generations. The search started with the set of different keywords, such as; "traditional grid," "smart grid," "renewable energy" and "centralized and decentralized systems of power generation." These keywords were used with various combinations by joining with "AND" parameter in the title bar of each database webpage. The "AND" parameter assisted in shortening down the search and bringing up the closest article related to the given topic. The articles and reports were selected by skimming the abstract and seeing the keywords mentioned in the articles. Further filtration criteria were the focus on 
technical articles while business articles on smart grid were excluded.

The second step related to further narrow down the articles and reports by screening each of them based on the technical characteristics, innovative technologies, advantages and disadvantages of smart grid. Further screening was applied to the following group of articles: 1) renewable and non-renewable energy sources and 2) articles that discussed centralized and decentralized systems of power generation. After screening and reading all those articles in detail, a valuable data had been found that leads towards analysis which can respond to the purpose of this study.

The final and third step was an "analysis" which was completed after filtering the data. The analysis is based on the following criteria: 1) performance, technical, and functional capabilities of traditional and smart grid and 2) Integration of renewable energy sources with the grid. The comparison had been performed between old and new energy systems to explore the modernized energy management system which can be adopted in the future. The criteria of this comparison were: 1) comparison between non-renewable and renewable energy sources based on the cost differentiation and eco-friendly and 2) comparison between centralized and decentralized of power generation systems based on cost differentiation and their functional capabilities. The analysis is a crucial component of this research which help to explore the transformation process of energy management system that can be exploited by the governments or energy providing companies. It enables them to fulfill the rising demand for electricity at comparatively less price without harming the environment.

\section{Comparison between Non-Renewable and Renewable Energy Sources}

Presently, renewable energy is a favorite subject of research. Population and energy demand are growing simultaneously. Non-renewable sources of energy are restricted, and fluctuations in non-renewable energy production have huge. Therefore inflation is high. Renewable sources of energy are plentiful, ecological and sustainable. In comparison with fossil fuels, renewable sources are self-restored. Renewable energy sources have their disadvantages identical to fossil fuels. The weather has a tremendous impact on renewable energy. The energy generated from this source could be decreased as a result of weather changes. Thus, people cannot shift entirely into renewable sources yet. Nevertheless, they can satisfy main part of energy demand by using renewable sources, which are advantageous for environment and economy [17]. Table 1 shows the differences between non-renewable and renewable energy sources.

According to Carolyn J. Randall [18], the climate of the Earth is changing; global temperature is going up because fossil fuels are burnt to produce electricity. The changes in climate and temperature are leading to the growth of sea level and melting of polar sea ice. Thus, renewable energy sources are a coming wave. Nowadays numerous countries are presenting special programs for 
Table 1. Comparison between non-renewable and renewable energy sources.

\begin{tabular}{|c|c|c|}
\hline Criteria & Non-renewable energy resources & Renewable energy resources \\
\hline $\begin{array}{l}\text { Repetitively used energy } \\
\text { sources }\end{array}$ & One-time use & Can use again and again \\
\hline Perpetual sources & Vanish one day & Available for perpetual use \\
\hline Eco-friendly sources & $\begin{array}{l}\text { Emits gasses and pollute the } \\
\text { environment }\end{array}$ & $\begin{array}{l}\text { Do not emit gases and does not } \\
\text { pollute the environment }\end{array}$ \\
\hline Availability & Limited quantity & Unlimited quantity \\
\hline Production cost & High & Low \\
\hline Maintenance cost & Low & High \\
\hline Production quantity & Large & Less \\
\hline Area required & $\begin{array}{l}\text { Require less space to install } \\
\text { energy plant }\end{array}$ & $\begin{array}{l}\text { Require large space to } \\
\text { install energy plant }\end{array}$ \\
\hline
\end{tabular}

development of renewable energy and for lessening emissions of carbon-dioxide. Research and development of renewable energy aim to increase efficiency and decrease electricity costs. In future, new technologies can transform to manage the power generation sources to meet the growing demand for electric energy. Finding resources of energy and plans for the development of sustainable energy needed to be maintained by the local community.

\subsection{Demand for Renewable Energy}

Tanaka [19] stated that the demand for electricity is rapidly increasing in the world. From 2007 to 2050 the projected consumption of power is estimated to increase by $115 \%$.

The demand growth of electricity varies between regions to regions. As Figure 1 shows that the demand growth of electricity in "organization for economic cooperation and development" (OECD) countries, is much more modest than the developing countries. OECD countries have higher demand, which causes higher growth rates. Due to declining the losses of transmission and distribution, as well as the development of infrastructure, smart grid technologies give advantages to OECD countries. Smart grid systems could be part of the new infrastructure in developing and fast-growing regions by providing efficient operations and better capabilities for market-function. Smart grid makes the delivery system more efficient in all areas. Smart grid has its role in demand reduction as well by providing consumers with data they can use to consume electric power more efficiently [20].

On the other hand, the demand for renewable energy is also increasing to fulfill the shortage of electricity. According to Kiefer [21], electricity delivery, utility market, and the traditional business models are being affected by the customer preferences. For instance, the amount of electricity has been reduced required from power companies by increasing the use of energy-efficient appliances, the massive growth of installing rooftop photovoltaic arrays. Banerjee et al. [22] use 


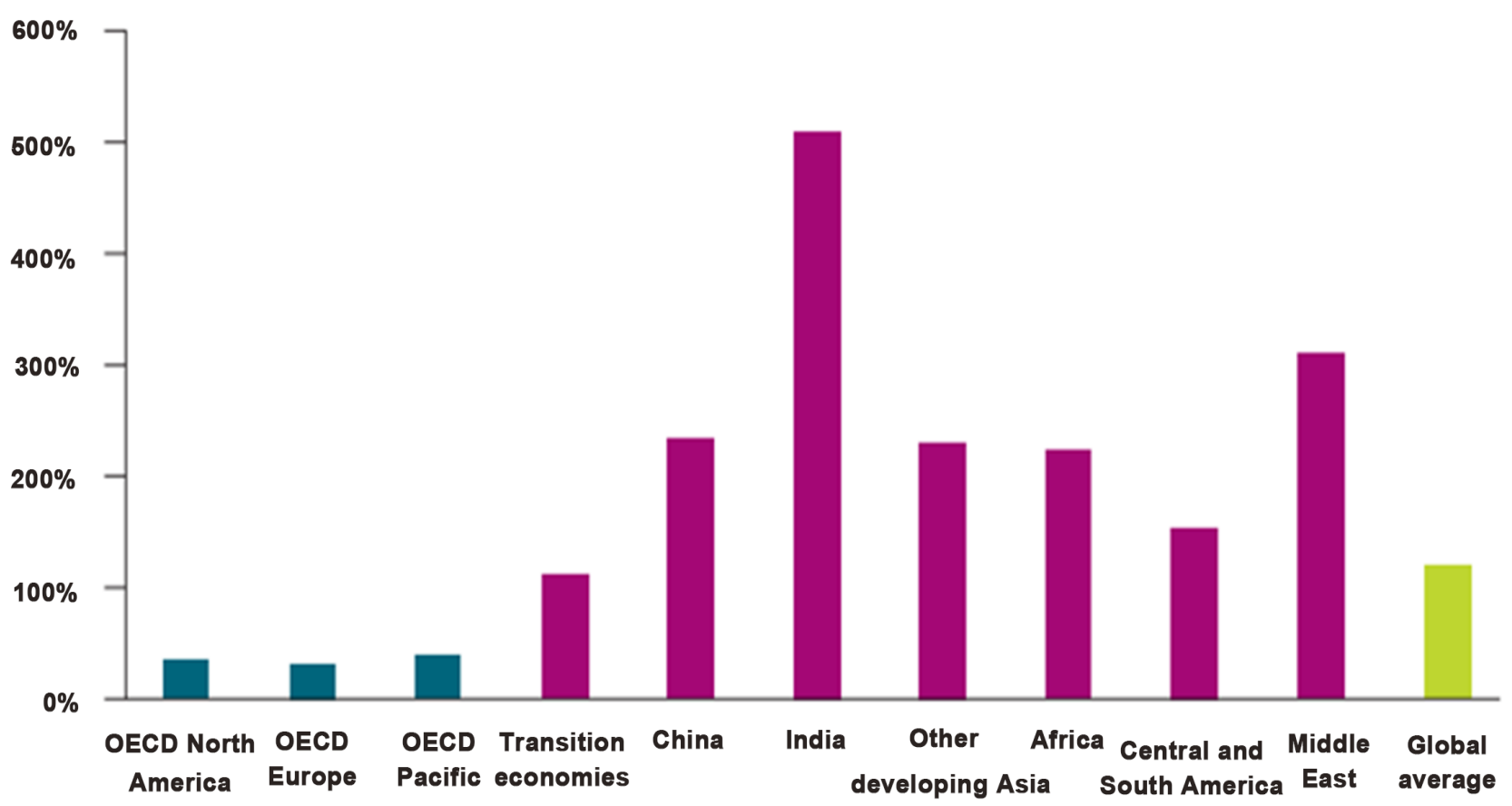

Figure 1. Electricity consumption growth 2007-2050 [19].

a word "prosumers" who both utilize and produce electricity. Furthermore, Banerjee et al. [22] claim that consumers are progressively becoming "prosumers." For instance, solar photovoltaic panels have been installed in the number of homes in the United States. It has been recorded that the solar photovoltaic installation has surprisingly increased from 15,500 in 2004 to more than 600,000 before the finish of 2014. It has been estimated that the solar photovoltaic system produced 1460 megawatts electricity for the residential use and more than $80 \%$ of that has been increased in the last four years.

As stated in Association [23] report, the rapid change and growth have been noticed of electro-mechanical to electronic-based devices, such as; offices, factories and home appliances which has directly been affecting on the requirement of energy and the grid operations. In this current era, $92 \%$ of transport is fueled by petroleum. However, the immediate rise of electricity demand has been predicted in the transportation sector, as the concept of plug-in electric vehicles is rapidly increasing. The $18.6 \%$ annual growth rate of the electric vehicle is being predicted from 2013 to 2022 if this prediction of electric vehicle sale continues then the demand for electricity will remarkably be increased. Concurrently, Banerjee et al. [22] suggest that the rise of electricity demand can be mitigated by installing smart meters, utilizing proper electric grid management techniques and time-based rates application. It encourages consumers to use electricity during off-peak hours which will save them from additional charges.

\subsection{Challenges}

The mindset of most of the stakeholders has been changed due to inefficient grid 
infrastructure, rising fuel cost, climate change, and the latest technologies used for power generation. Feisst et al. [24] raised some questions which have become challenges for the power suppliers:

- The most prominent issue for the electric supplier is to reconsider about the future electrical system, as the centralized electric generation system becomes the primary cause of emitting around 25 percent of global greenhouse gases.

- Another important thing is to consider, the role of distributed electric generation and the integration of renewable energy with the electric grid will remarkably be prominent in the reduction of greenhouse gas emissions.

- Next challenge rises at the demand-side management to reduce power consumption and enhance power proficiency.

- Constant monitoring of grid performance can improve blackouts, utilization, and grid reliability. Furthermore, constant monitoring would be a challenge, but it will rapidly return the financial investments on the grid.

- The remarkable rise of electricity demand, the emitter of greenhouse gases and dependence on fossil fuel which are against eco-friendly have become noticeable challenges. Renewable energy sources have been addressed to generate electricity as the usage of fossil fuels pollutes the environment [25].

- Traditional grid does not have an appropriate capacity to fulfill the increasing demand for electricity. Massive modification and improvements are required to integrate renewable energy sources with traditional grid to generate electricity [26].

\subsection{Opportunities for Improvement}

Technology plays a decisive role in enabling the electrical system to be more efficient. Electrical reliability can be improved; greenhouse gas emissions can be reduced by just implementing advanced applications and technology [24]. Some of the opportunities where improvements can be made in the electrical system are mentioned below:

- Advanced technology and application software can help reducing power usage during peak hours by robotically turning off specific home appliances, office equipment, and factories machinery.

- Instant feedback can help reducing wastage of energy consumed by the consumers.

- Usage of energy can be reduced by producing smart appliances by the manufacturers.

- Power blackouts can be controlled by installing sensing equipment and detaching turbulences in the grid.

It is not hidden that non-renewable energy sources are restricted and fluctuation is huge during energy production whereas renewable energy sources are unlimited, ecological and sustainable. Furthermore, the remarkable rise of electricity demand, the emitter of greenhouse gases and dependence on fossil fuels have become noticeable challenges. Meanwhile these challenges have created tremendous opportunities for the improvement of power generation and distribution systems which can be restructured, modified and equipped with innovative technologies that can satisfy the rising demand of electricity and mitigate greenhouse gas emissions in better and efficient way. 


\section{Power Generation Systems}

Decentralized decision making enters the higher level of the power system, which is caused by continuous reformation of the electricity industry. The planning of long-term growth is influenced by the trend of improvement because now private investors with smaller centralized direction are making significant decisions [27]. The power plants have been centralized and using heavy and costly components to produce electricity. According to Alanne et al. [28]], the generation of distributed energy leads to this new tendency, which means that heavy power generation components are switched into smaller components, and energy generation elements are near to end-users of the energy. The term distributed generation of energy includes self-operating buildings as well, which could provide themselves with electricity, cooling and heat energy. Alanne et al. [29] state that the alternative of the original system of electricity is the system of distributed electric power, which is more reliable, efficient and sustainable. For instance, hospitals have implemented this concept since continuous electricity distribution is crucial for them. Another example of generation of distributed energy is automobiles [30].

\subsection{Centralized Power Generation System}

The electricity was produced by big power generators in the 1900's, which were located in central areas. In this period, electricity reached to end-users through networks of transmission and supply. Alanne and Saari [28] bring an example of a classic centralized system (Figure 2) of electric energy, which includes a large number of end-users located in big distribution zone.

Figure 2 represents the complete scenario of centralized power generation system. Energy is produced at the central point and then it is transmitted through the high voltage electric wires to the grid and from there electricity is distributed to its consumers. The transportation of electricity is costly and are more chances of interruption during power supply.

The generation of electricity through central power generators is called centralized generation (CG). These generators provide the power of bulk. To get steam necessary for operating generators of the turbine, most of the power generators use coal boilers or fossil-fired gas, or nuclear boilers. Sometimes large hydro is used as well. Costly execution of large infrastructures is needed for these massive power plants. Unpredicted events and uncertainty are the serious issues for CG power plants. Thus, CG power plants are unprotected from errors and attacks.

Momoh et al. [31] state that CG power plants' efficacy, security, and benefits are not sufficient for this modern era, which intensifies the efforts of authorities and researchers to look for sources of renewable energy.

\subsection{Decentralized Power Generation System}

The generation of electricity, which is located close to end-users, is called decentralized generation (DG). Sources of DG contains technologies, which are 


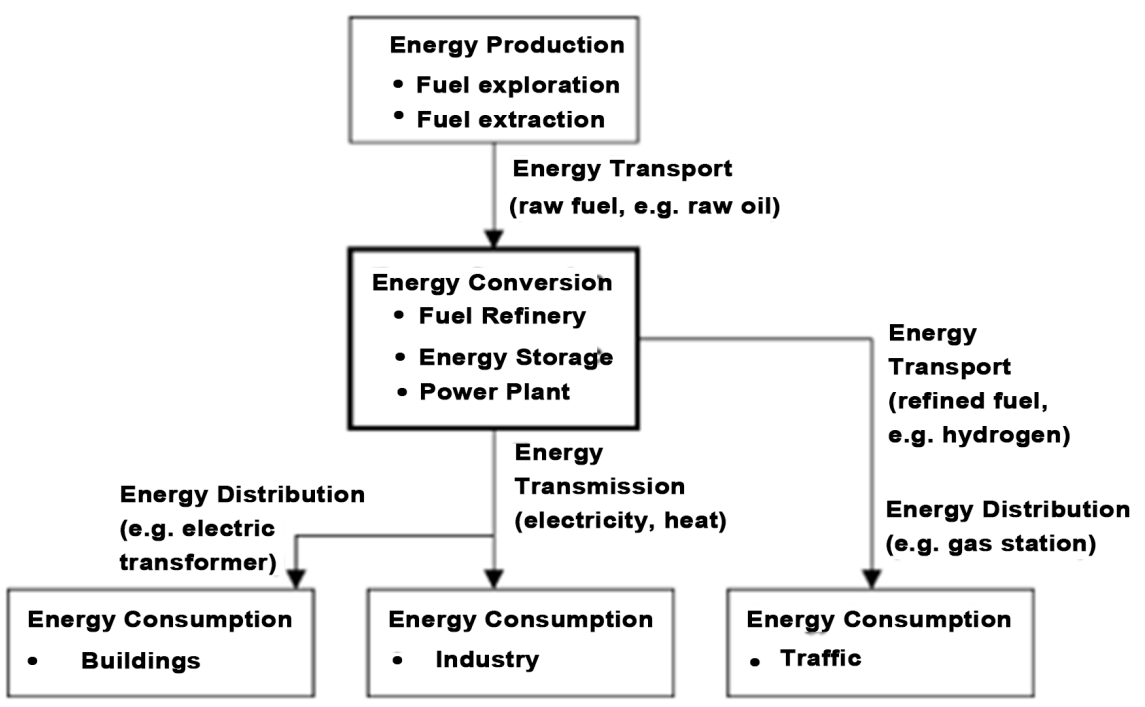

Figure 2. An illustration of a centralized power system [28].

small-scale and ecological, for instance, photovoltaic and wind technologies. These technologies are originally installed and made for serving in a specific location of the individual consumer [31]. Alanne and Saari [28] argue that even though energy transmission and supply are based on the location of electricity generators, naturally the consumption of energy is decentralized or distributed. The concept of "decentralized" or "distributed" is connected with the way separated units are combined and form the entire system, as shown in Figure 3.

Figure 3 shows that even in the small area electricity can be produced and utilized in each separate unit. These units are combined through one central control system where information can be exchanged and energy can be stored and distributed according to the demand of the consumers.

Decentralized power generation systems contain reciprocating engines working on traditional fossil fuels or gas turbines to enhance the quality and reliability of the electric grid [31]. The connection between electrical grid and DG is creating reliability and security issues for utility. DG could decrease the demand for traditional utility services. For incumbent utilities and end-users DG creates economic risk as well. This risk could be managed only with procedures for cost recovery or with proper rate structures. Occasionally, DG which is arranged and designed efficiently gives numerous advantages to society and end-users. For example, cost savings due to subsidies from government and a cleaner environment. DG is installed in multiple utility systems, and it has its significant role in the development of new technologies [31].

\subsection{Localized Power Generation System}

The localized units do not have a connection with other units. Thus, they are stand-alone and independent [32]. It is significant to realize that all localized generation (LG) systems are decentralized or distributed, whereas not always decentralized or distributed systems are localized as it is mentioned in Figure 7 


\section{Local energy consumption}

(e.g. a block of buildings)

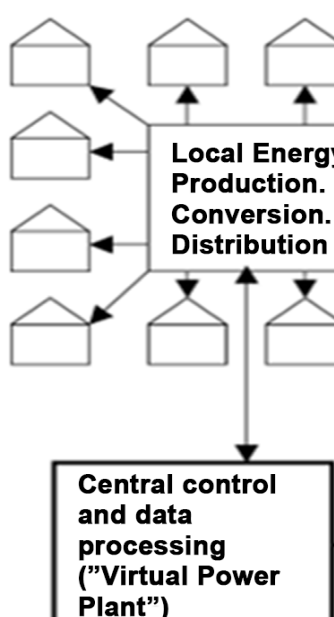

Plant")
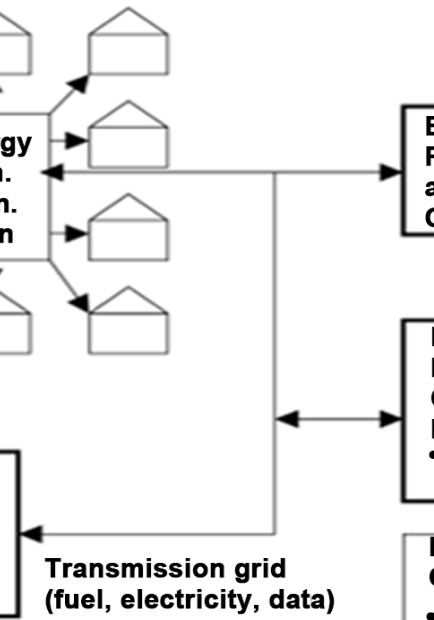

Single energy consumption

(e.g. building. factory)

Figure 3. An illustration of a decentralized/distributed power system [28].

that decentralized systems are the combination of small units. Therefore, in energy systems context, using the word "decentralized or distributed" is more rational. Figure 4 clarifies the localized energy system example.

Figure 4 shows an example of the localized power system. As represents in Figure 4, it is possible that the whole chain of electric power could be combined in one place. For example, it could be a building, which is in countryside regions and the building is not connected with the network of public energy. The building contains solar electricity system, electricity distribution including storage of electricity and heating system which is a good picture of a localized generation of power [33].

\subsection{Comparison between Centralized, Decentralized and Localized Power Generation Systems}

In order to design a series of activities for future grid, the comparison has been done based on the criteria which is mentioned in Table 2.

It gives an opportunity for designing a workable grid, which will satisfy increasing global electricity demand. Moreover, essential requirements, development of abilities and arrangements of institutions are combined into special road map. The road map has an objective to increase the engagement of population in new smart grid [31].

As per Table 2, the measurement standard for CG/DG and LG comparison contains combined infrastructure resiliency assessment, the effect on sustainability through CG/DG and LG because it is concerned with energy decreasing, environmental effect reduction and emission declining. The criteria include the finding of efficient CG/DG and LG combination as well, which will satisfy the needs of future grid. The installation of DG is affected by obstacles, such as: problems with quality of power, generation of power and high cost, because subsidy from government or local sources may be not sustainable. 

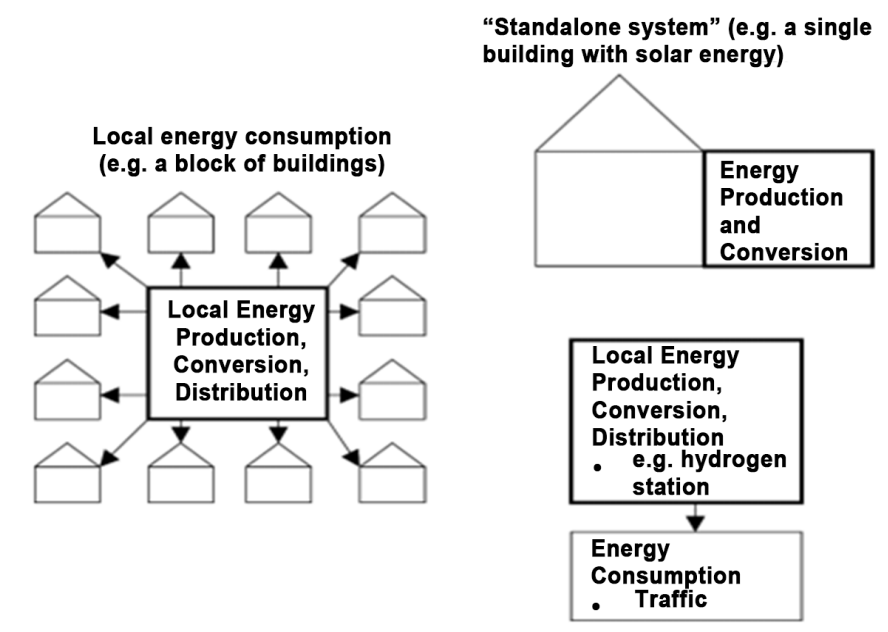

Figure 4. An illustration of a localized power system [28].

Table 2. Comparison between centralized and decentralized power systems [31].

\begin{tabular}{|c|c|c|c|}
\hline Criteria & Centralized Generation & Decentralized Generation & Localized Generation \\
\hline $\begin{array}{l}\text { Uninterrupted } \\
\text { Power Supply }\end{array}$ & $\begin{array}{l}\text { Although CG system provides uninter- } \\
\text { rupted power supply, but the attributes } \\
\text { of CG are showing the } \\
\text { following results: } \\
\text { - Because of high losses at the system } \\
\text { of transmission, electric } \\
\text { effectiveness is low. } \\
\text { - Emissions are high. }\end{array}$ & $\begin{array}{l}\text { DG allows buildings to generate their own } \\
\text { permanent electricity. Essential DG } \\
\text { features for uninterrupted power } \\
\text { generation gives following results: } \\
\text { - Electric effectiveness is high. } \\
\text { - Emissions are low. }\end{array}$ & $\begin{array}{l}\text { LG permits pump stations/hospitals } \\
\text { or any isolated building to generate } \\
\text { their own electricity. } \\
\text { - High efficiency. } \\
\text { - Low emission required. }\end{array}$ \\
\hline $\begin{array}{l}\text { Premium } \\
\text { Power }\end{array}$ & $\begin{array}{l}\text { Reliability of power supply is low. There } \\
\text { is no assurance of high quality power } \\
\text { because power losses are high. }\end{array}$ & $\begin{array}{l}\text { Electricity generation and delivery are } \\
\text { more reliable and have higher quality than } \\
\text { usual electricity which provided by grid. }\end{array}$ & $\begin{array}{l}\text { Supply of power is reliable as power } \\
\text { generation is very close to end user. } \\
\text { No chances of losses. }\end{array}$ \\
\hline Cost & $\begin{array}{l}\text { - Changing cost is high. } \\
\text { - Maintaining is very costly. }\end{array}$ & $\begin{array}{l}\text { - Changing costs are low. } \\
\text { - Maintaining is not costly. }\end{array}$ & Low charging and maintenance cost. \\
\hline Peaking Power & $\begin{array}{l}\text { Has unstable functioning at different } \\
\text { peak levels of power. }\end{array}$ & $\begin{array}{l}\text { Functioning from } 50 \text { to } 3000 \text { hours every } \\
\text { year for decreasing costs of electricity. }\end{array}$ & $\begin{array}{l}\text { Same as decentralized } \\
\text { generation. }\end{array}$ \\
\hline Resiliency & $\begin{array}{l}\text { Have less resiliency but meets high } \\
\text { demand of power. }\end{array}$ & $\begin{array}{l}\text { Are more resilient due to satisfying low } \\
\text { demand of power. }\end{array}$ & Same as DG. \\
\hline Sustainability & Less sustainable due to power sources. & $\begin{array}{l}\text { Are sustainable due to renewable sources of } \\
\text { power. }\end{array}$ & $\begin{array}{l}\text { Sustainable as solar panels depend on } \\
\text { sunlight. }\end{array}$ \\
\hline
\end{tabular}

\subsection{Cost Differences for Centralized, Decentralized and Localized Power Generation Systems}

Comparison of costs based on typical design, required for CG/DG and LG is now becoming very important since DG/LG engage new technologies. Expansion of DG role in the future grid could be built on whether DG/LG costs are lower than CG because DG/LG is permanent energy providing source. DG/LG power would be closer to the retail price of produced electricity, and it would be more efficient for satisfying the demand of small power markets due to the same location of electricity generation and usage. DG and LG replace the power pro- 
vided by the utility which is less probable for DG and LG to affect users of land negatively [34].

Table 3 represents the cost in cases of using centralized, decentralized and localized power generation systems. The power supply area is the same in these cases. DG/LG systems are based on technology which has the lowest cost if heat loads and permanent electricity are accessible. Through limiting technologies which are accessible to the model, efficient solutions for DG/LG using system can be compared with a system using electricity-only and heat-only technologies [31]. The question is, will DG/LG systems provide cost savings?

The installation and maintenance are very costly for CG systems. The usage of CG is based on central location. From installation and maintenance perspective, CG is less costly than DG but LG is much more lesser than CG. In the same area, power distribution through CG is cheaper than DG whereas LG is within an isolated or standalone building so no distribution system required. However, DG/LG have less power losses than CG [35]. Moreover, CG and DG/LG combination would have more cost savings. Areas with huge population should be a priority for using both CG, DG and LG. In the regions with huge population, CG could be used for reducing power losses by locating it very close to the areas or DG/LG could be used for lessening the losses. Therefore, capital costs could be decreased due to less installation capacity of CG or DG/LG systems.

Table 3. Cost differences between CG and DG systems [31].

\begin{tabular}{|c|c|c|c|}
\hline Component Cost & $\begin{array}{l}\text { Centralized } \\
\text { Generation }\end{array}$ & Decentralized Generation & $\begin{array}{c}\text { Localized } \\
\text { Generation }\end{array}$ \\
\hline Capital cost & Per unit low cost & $\begin{array}{l}\text { - Cost is high for every } \\
\text { unit. } \\
\text { - Cost saving through } \\
\text { system design and } \\
\text { capacity reduction. }\end{array}$ & $\begin{array}{l}\text { - Per unit cost is } \\
\text { high. } \\
\text { - Life time cost } \\
\text { savings from } \\
\text { utility bills. }\end{array}$ \\
\hline $\begin{array}{c}\text { Maintenance and } \\
\text { Operational cost } \\
\text { (Fixed) }\end{array}$ & Higher & Lower & Lower \\
\hline $\begin{array}{c}\text { Maintenance and } \\
\text { Operational cost } \\
\text { (Variable) }\end{array}$ & Lower & Higher & Lower \\
\hline Fuel & Highly required & Not required & Not required \\
\hline Transmission & $\begin{array}{l}\text { - Mandatory high } \\
\text { voltage } \\
\text { transmission } \\
\text { - } \quad \text { Failure of } \\
\text { transmission and } \\
\text { high losses }\end{array}$ & $\begin{array}{l}\text { - Only distribution is } \\
\text { needed } \\
\text { - Decreased cost } \\
\text { of capital }\end{array}$ & $\begin{array}{l}\text { - Production is } \\
\text { close to } \\
\text { end-users. } \\
\text { - Cost saving on } \\
\text { distribution. }\end{array}$ \\
\hline $\begin{array}{c}\text { Unnecessary Expense } \\
\text { based on unserved } \\
\text { energy }\end{array}$ & High & Low & Very low \\
\hline
\end{tabular}




\subsection{Analysis and Reflection}

Centralized, decentralized and localized grid systems have advantages as well as disadvantages. Thus, the purpose is to discuss the advantages and disadvantages as well as to identify problems, which grids could create. This debate leads to explore the proper solution in upgrading existing mechanism of grid which makes the grid more secure and efficient.

In general, some decentralized and localized systems of generation are distributed geographically. Thus, it is possible to place them very close to areas where end-users are living which decreases the cost of supply and transmission of electricity. Strong terms build on multiple separate generators and their reliability, in comparison with CG, shrink the transmission and supply costs [36]. In the system of CG, power transmission goes through a long way to reach end-users. At the final stage of generation, various sources should produce electric power. For example, thermal power, nuclear power, hydropower. The need for transforming CG into DG is high especially in areas, where CG system is very far from consumers. This approach decreases power transmission losses [31].

An alternative method exists for saving costs. It is localized DG. Part of electric energy, which used to be lost during energy transmission in CG, is now saved because of generating the energy close to the place where it will be used. The quantity and size of needed power lines are decreased as well due to this approach. The preservation of distributed energy sources in a Feed-in Tariff (FIT) scheme is low.

They have low contamination, and they are efficient. Nevertheless, the quality of electric power and security become critical issues in this case, because of most of FIT's need using renewable resources, which are discontinuous. For less pollution, DG and LG require complicated plants and professional engineers. Due to sustainable resources (sunlight, geothermal, wind energy) and automatic functioning, contemporary embedded systems can face these challenges. This approach decreases the number of power plants, which could give profit [37].

The rapidly growing demand for electricity requires reliable power grid. The grid is using various modern power generation mechanisms to make the electrical system influential, sustainable, protected and flexible where technology needs more Distributed Generators. The same could be said regarding the CG. Nonetheless, the installation of CG becomes more difficult and costly because of higher installation, permission and location barriers. Therefore, with growing electricity demand, the implementation of DG and LG is inexpensive than installing CG. Moreover, during new power generation place construction, using CG is very expensive and economically ineffective (costs for power transmission). DG and LG, which is not intermittent, does not require a system of transmission. Thus, it completely removes costs for transmission. Therefore, for new power plants construction, it is evident that DG and LG show more efficacy and cost savings compared with CG [38]. 
The centralized power generation system uses coal boilers and fossil fuels which emits gasses. Cost of transmission and execution of heavy power generation plants is high, completely insecure and not able to be efficiently integrated with renewable energy sources. On the other hand, decentralized and localized power generation systems are located close to the end-users which decrease the transmission and supply cost, it can easily be integrated with innovative technologies and renewable energy sources, reduces the cost of utility services and providing clean energy.

\section{Early Electric Grid}

Thomas Edison's Manhattan Pearl Street Station was the earliest electric complex in the world. It started to run in 1882. Originally, Edison's electrical complex was a microgrid, which contained $100 \mathrm{~V}$ coal-fed electric engine. It was providing electricity to few hundred lamps. Thus, electric grid was compact and limited in the early stages [39]. Power plants were located near to their power sources in the first instance of electric complexes. Figure 5 is a reflection of an early electric grid.

They were within close range of their ultimate users as well. Nevertheless, throughout time, the demand for electricity has been grown up. Thus, these small grids were evolved into larger and more compound systems. Appropriately, electric grids were transformed into interdependent systems. Now we are using these systems, and they are connecting the stations of power generation, load centers, supplying channels and lines of transmission [40].

\section{Traditional Grid}

The word 'grid' is usually used for an electrical system. Traditional grid supports typically four operations, such as electricity generation, transmission, distribution, and control. The primary function of traditional grid is to carry electricity from the point of generations and distribute it to many of its consumers by using transmission lines [41]. Banerjee et al. [22] explain that the architecture of traditional grid was constructed on the extensive amount of electricity generation, passive loads, centralized and one-way control.

Most of the electricity grid or power supply system in the world was built when the cost of electricity was reasonably low. The grid has still been functioning as it had been functioning almost hundred years ago, to fulfill the rising demand for electricity, minor upgradation has been done. Energy is generated at the central electricity plants then it flows over the grid to consumers, and there is no proper storage surplus capacity [26]. Hossain et al. [42] add that more likely traditional grid would not have the sufficient capacity to fulfill the future demand for electricity. Furthermore, the existing grid system emits greenhouse gases, consumes lots of fossil fuels which is completely a useless and environmentally extravagant system. Thus, it is not suited to distributed, wind energy and renewable solar sources.

\subsection{Traditional Grid Design}

According to Banerjee et al. [22], a decade ago, organizational principles and system design models were used to design and build traditional grid system. It 


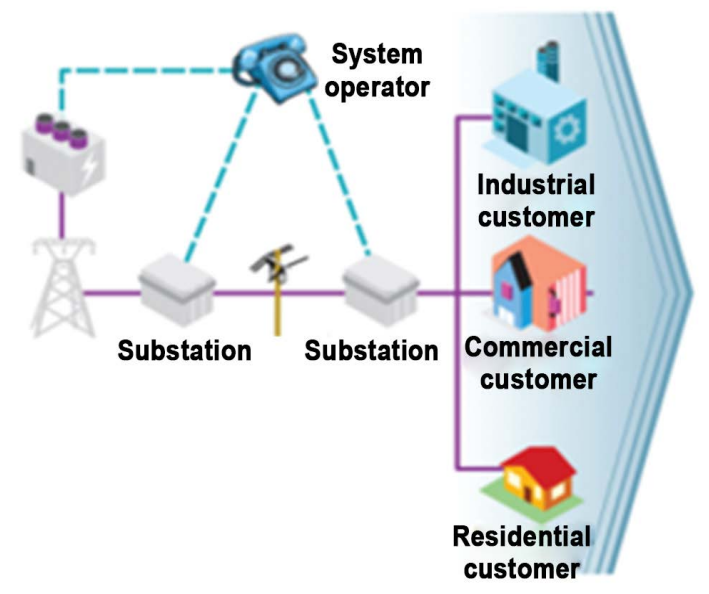

Figure 5. Early electric grid [22].

should have been restructured to achieve the demand of digital economy, low-carbon and environment-friendly. Traditional grid design was depended on a large scale generation, passive loads, energy storage with limited capacity, minimal feedback due to hierarchical control structures and remotely located from consumers. Figure 6 shows the graphical view of traditional grid architecture.

Traditional grid does not have the capability to adapt the upcoming technology, such as; power generation sources with low inertia, the demand for greater flexibility and the distributed power generation resources of rising diffusion.

The latest studies reveal that a smart grid is fully equipped with agile, robust and more flexible. Resources and grid operators can dynamically be optimized in a smart grid system; disturbances can rapidly be detected and mitigated, diversely integrated with energy generation sources and able to protect against cyber and physical risks. Moreover, consumers are in-charge to manage the use of the electricity and finally, smart grid can response the demand and the energy resources can efficiently be integrated according to the need [22].

\subsection{Analysis and Reflection}

The analysis and reflection of traditional grid have been done based on its characteristics. As it is demonstrated in Figure 7, traditional grid is a rigorously hierarchical electrical supply system. In this system, the central generation is at the top of the chain where electricity is produced, and the customers' loads are at the bottom of the chain where electricity is supplied [43].

Traditional grid does not have two-way communication because it is fundamentally a one-way channel system. The source does not have immediate information if the electricity is terminated at the customers' end. Furthermore, the grid is incompetent to bear maximum load if it exceeds its projected demand. Thus, it is integrally an ineffective system.

Additionally, the system stability has been decreased because of the ineffective infrastructure of power delivery system and the tremendous rise in demand for 


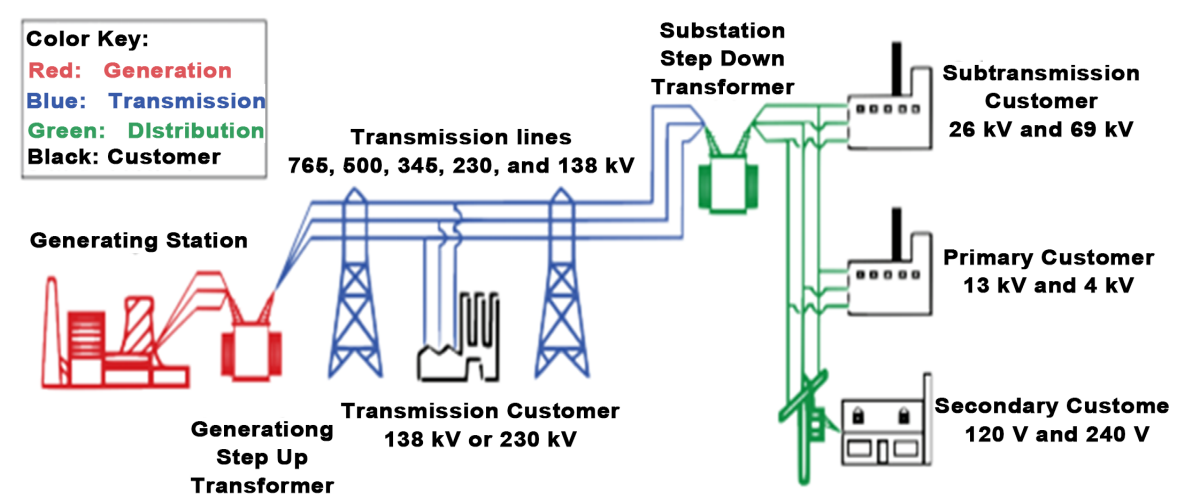

Figure 6. Traditional electricity delivery system [22].

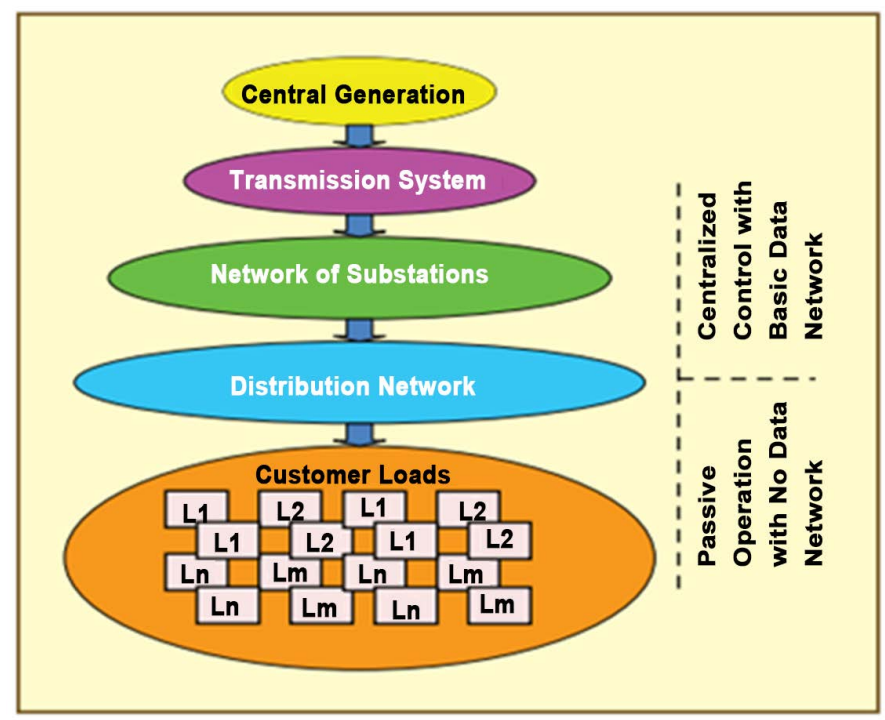

Figure 7. Traditional grid [43].

electricity. Finally, terrible blackouts can be activated because of the failures of the components which could be the cause of irregularities in distributing power supply.

In this modern world, traditional grid has now become a "stupid," ineffectual and environmentally extravagant system, because it is fundamentally a one-way channel system. The power distribution system cannot receive immediate information if the electricity is terminated at the customers' end. The grid is incompetent to bear maximum load if it exceeds its projected demand. Moreover, it is not suited to integrate with decentralized/localized and renewable power generation sources. Therefore, traditional grid does not have sufficient capacity to fulfill the increasing demand for electricity.

\section{Technology Development}

Innovative technology has made it possible that traditional grid can be transformed into smart grid. This technology can be divided into three main segments: generation, transmission, and distribution. Technology that belongs to generate and transmit electricity is rapidly developing and improving as it is 
controlled by the utility companies whereas, distribution segment is facing a huge struggle on some of the improvements, some stakeholders are involved in this part of the process [44]. According to Kang et al. [45], energy efficiency is directly associated with the technology. If the technology is advanced, then the better level of energy services can be achieved by using less energy. Hi-tech equipment which contains efficiency measures is useful for energy saving and long-lasting use if they are used at the consumer's end. Kempener et al. [46] stated that embedding smart equipment into the grid is the only way to transform the electricity system, as shown in Figure 8.

Figure 8 shows that the present grid has an only one-way communication system. It does not have system that consumers can send information to grid or its utility providers. On the other hand, the future grid is a fully integrated two-way communication system and has various types of distributed power generation system. Future grid is fully equipped with smart technologies which enables its consumers to send or receive information from the grid [46].

Furthermore, Prabhu et al. [8] stated that major changes are required in the distribution network, specifically for residential and commercial consumers. Main technology requires for distribution networks are special charging equipment for an electric vehicle, transformers that has a built-in high efficiency of the distribution system, smart meters, low voltage inverters that have the capability to integrate with solar systems, automation systems for homes or buildings and automatic fault detecting sensors. Other significant technologies which brought smart gird into existence are mentioned below:

Communication Technology: Communication technologies made possible for different smart electronic devices to integrate and interact with each other. It includes protection, data transfer and allows consumers to communicate with the intelligent devices [47]. According to Luan et al. [48], smart grid systems can use ethernet based networks to communicate with different devices. However, Ethernet-based networks are not suited to establish everywhere because it is a wired system network [49]. Furthermore, as per Deb et al. [50], cloud computing has brought great evaluation in communication technologies. Fuzzy controllers have the strength to enhance the robustness of the system.

Sensing Technology: Sensing technology plays a significant role in measuring and evaluating the integrity and health of electric grid. Sensing technology has the capability of preventing energy theft, eliminating the billing estimation system and automatically taking meter reading [47]. Furthermore, complex energy

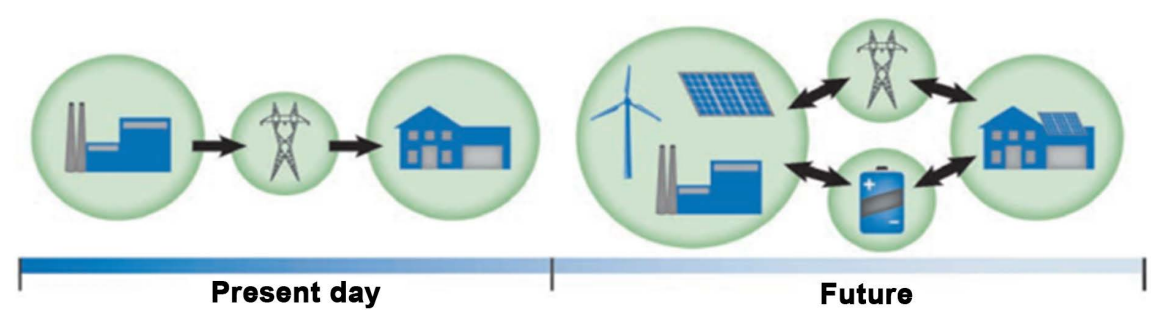

Figure 8. Transformation of electric grid through innovative technology [46]. 
system data can be converted into a readable format with the help of sensing technology which can easily be comprehended by grid operators.

Fault Detection Technology: Fault detection technology enables the grid to indicate the disturbance and faults in the grid. In case of any disruption, this technology helps the system to restructure the grids in affected areas and re-adjust rapidly with the newly assigned network topology which allows the system to reduce the severity of the disturbance and faults of the grid. Furthermore, in case of any major disruption in the power system which leads to an emergency, the system should take prompt action and redirect the power to normal and secure paths [51].

Power Storage Technology: Innovative technology has brought an evolution in grid systems. Power storage technology is one of the great examples of it. According to Katiraei et al. [52], renewable energies such as; photovoltaic battery, wind power, storage components and fuel battery required more control functions. Power electronic converters are used to connect these energy sources with the large-scale power grids. Prabhu et al. [8] stated that Energy storage technologies have a high capability to integrate with renewable energy sources which help to mitigate the demand for electricity. Operations can be optimized, efficiency can be increased, and distribution systems and flexible transmission can accommodate fluctuations in supply. Furthermore, disruptions of electricity can be prevented before they occur with the help of strict control system and automatic monitoring system.

Weather Predicting Technology: Some of the sources of renewable energy based on weather. Therefore, the demand for cutting-edge technology in weather forecasting is mandatory. To accurately predict the changes in power generation of renewable energy, it is required to enhance the precision of climate forecasting technology. Thus, the instability of renewable energy in producing power will be reduced [9].

Other Advanced Technologies: Some of the other innovative technology helps to build up a complex smart grid system. It also assists to monitor the performance of the grid. The advanced methods are the algorithm that allows to predict, diagnose and analyze grid conditions which are used to take rapid actions against blackouts, power quality disturbance and mitigate power shortage [47]. Furthermore, Li and Yao [9] say that even though the access of renewable energy distribution system is complicated but the advanced technology made possible to monitor, control and schedule in stable operation, safe and improving efficiency.

Innovative technology has brought marvelous revolution in an electrical industry. It made it possible for the grids to integrate with centralized and decentralized power generation systems. With the help of digitalized technology traditional grid can be transformed into smart grid which enables smart devices to interact with each other, measuring and evaluating the integrity and health of electric grid. Technology has the capability of preventing energy theft, eliminating the billing estimation system, automatically taking a meter reading and enabling the grid to indicate the disturbance and faults. Furthermore, energy storage technologies have a high capability to integrate with renewable energy sources which help to mitigate the demand for electricity. 


\section{Smart Grid}

The aging of traditional grid, the lack in responding to the increasing demand of electricity, instability in fuel cost and no automation system for power restoration has brought an idea of "Smart Grid" (modernized electric distribution system). Smart grid can be fully equipped with innovative technologies and be able to fulfill the future demand for electricity [16]. Forte [53] added that smart grid is a system, combination of innovative sensors, two-way communication system, automatic metering, intelligent electricity supply equipment and completely computerized system. Smart grid has the capability to improve choices and awareness for the consumers, consistency in the performance of electric supply and enables utility providers and consumers to take independent decisions in delivering and receiving services. Figure 9 shows the complete overview of smart grid.

According to Chang et al. [54], smart grid system can quickly adapt revolutionary enhancements in economics, reliability, efficiency, and sustainability of different electricity services. Advanced metering infrastructure is considered as a central point of information flows in smart grid systems. Furthermore, Horowitz et al. [55] explain that the beauty of smart grid is that, networked intelligent sensors can be integrated with long-distance transmission lines which can be profited in increasing efficiency, improving operations and synchronizing alternative and even small power sources.

Forte [53] stated that, by enabling the core functionality of plug-in electric vehicles, renewable sources, micro-grids and of other technologies would make it possible for smart grid to penetrate and integrate with these technologies. Finally, Prabhu et al. [8] say that smart grid can fulfill the future demand for electricity and the need for power for electric vehicles. Moreover, it is well capable of keeping environmental concerns.

\subsection{Conceptual Model of Smart Grid}

According to Li and Yao [9], the primary function of the electric grid is to deliver electricity from the generation point to consumers. The delivery of electricity network mainly works through the transmission and the distribution systems. Electricity is transmitted through transmission system from electric generation plants to distribution substations whereas electricity is distributed to consumers from distribution substations through the distribution system, as shown in Figure 10.

The conceptual model of smart grid is represented in Figure 10. It is a combination of a different set of domains, and each domain has its function according to its communication and electrical interfaces. Besides that, smart meter plays a vital role in overall communication between electrical grid and consumer interfaces; it consists of the communication link and an electronic box. A smart meter electronically records the necessary parameters and the consumption of electricity consumed by consumers, then time to time it transmits the recorded 


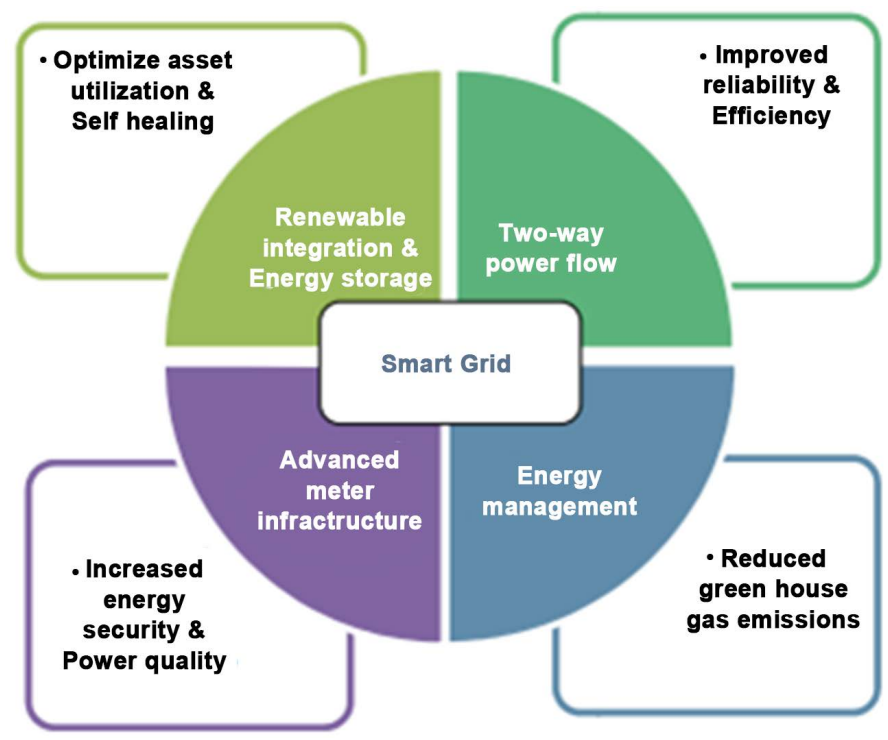

Figure 9. Smart grid benefits [25].

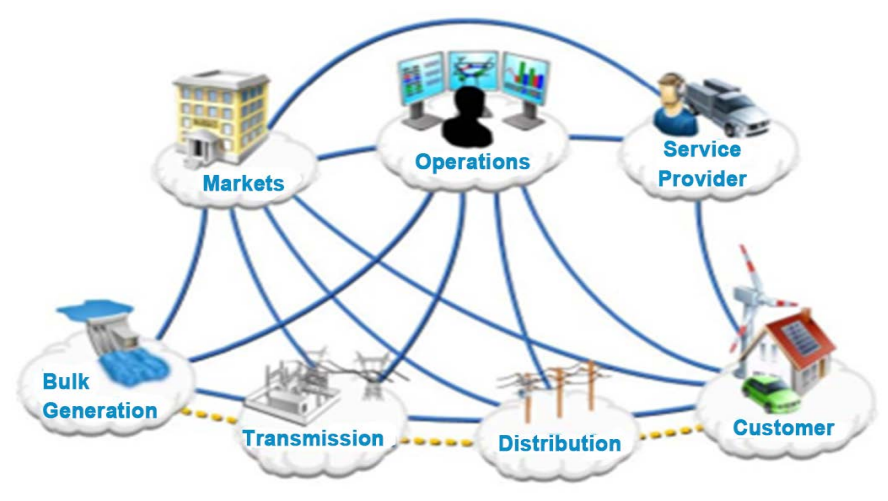

Figure 10. Conceptual model of smart grid system [9].

information over a communication network to the billing providing companies. Similarly, the information can be supplied through end-user devices to the consumers for informing them regarding the related costs and the energy consumption [11]. Moreover, YIN et al. [56] stated that smart meters could be differentiated according to their features and capabilities, such as; one or two ways communication types, meters that can measure the storage data or the meters that can be connected at the energy suppliers' end.

\subsection{Integration of Smart Grid with Renewable Energy}

The over-reliance on fossil fuels and the growing demand for energy are becoming significant problems presently. Thus, for generating electricity, there is a huge tendency for switching to renewable energy. However, to adapt and combine these disconnected natural sources, important developments and adjustments for current electric grids would be required [25]. Renewable energy sources, including solar, wind and others, cannot be distributed naturally. Furthermore, changes in weather have a giant impact on the renewable energy 
sources. These create gaps and instabilities, which will affect original grids, as they have quick changes and alteration of voltage, as well as regularity changes. Nonetheless, smart grids will launch a computerized network of data due to smart detectors, automatic systems of transmission and resolution [51]. According to Papavasiliou et al. [57], nowadays the adoption of sustainable sources of energy by smart grid system is becoming supreme and significant, which is gaining more attention of researchers.

Atteya et al. [58] argue that smart grid has more essential functions besides sustainable energy unification and depository of energy in a system distribution. Other principal tasks are monitoring, smart metering, systems of communications, as they help to get data about power usage and send it to electric services through a wireless network of communication to execute and examine the information for making effective decisions for consumers and utilities. According to Vallee et al. [59], combining sustainable sources of energy into smart grid is allowing to save the sources costs regarding construction of additional generators. Moreover, it is enabling to enhance the quality of power, fulfills needs of customers and makes the system reliable. Gaviano et al. [60] combined data and analyzed smart grid's role in generating renewable energy and its potential for future studies. The authors state that central and crucial element in connecting and adjusting renewable energy for construction of future grid is the interaction between digital devices.

Ultimately, Smart grid control allows to sustain functioning of the system, foresee expected performance of it, manage resource supply, safety, demand, efficient reply to digital devices, and decrease the operation costs [61]. According to Liserre et al. [62], the future of security and execution systems is smart grid, which is auto-controlled, reliable and stable.

\subsection{Techniques Apply in Smart Grid}

The techniques that make smart grid "smart" are expressed here. According to $\mathrm{Li}$ and Yao [9], smart grids, which are systematized, have to respond to power variations and forecast the defects of operating systems. Multiple remote sensors are developed to reach this point. Communicating grids are being inserted in the original transmitting grids. The method of communication has an accurate and flexible standard of measuring because every inadequacy in the system should be fixed swiftly [63].

Automated Metering System: Smart grids must manage consumer changes for holding the stability of consumers and providers. The electric meters are forming the improved metering system by intelligent system of data-execution at the supplier end. According to Yu et al. [64], the nexus which links them has the following tasks: maintaining adaptable price for the electricity power, automate control of electric load based on current time price, computing actual time information for users, power quality and voltage remote control.

Computerized Electrical Devices: The smart digital devices, machines of power supplying with adaptable systems of transmission and the solid-state con- 
trollers, which are multifunctional, are all technical devices. They have vital roles in generating, transmitting, providing and utilizing of electricity. According to Li et al. [9], the most widespread controller of power grids is silicon switches. In smart grids, they will be used as integrated instruments with multiple functions and with real control for making the ability of transmission to the maximum.

Digitalized Transmitting and Distributing System: The improved mechanization contains generators with an efficient measuring system of large zones and other vital processes. This mechanization can upgrade functioning and execution of smart grids. Yang et al. [51] state that the developed automation of transmission and supply could preserve grids' performance, self-recovering, and management throughout swift and updated programming.

\subsection{Characteristics of Smart Grid}

As per Xie et al. [65], smart grid uses the self-scanning technique to inspect, identify, as well as to repair its elements or units of the network. By these operations, smart grid preserves safety, accessibility, quality of power and its state of energy-saving. Smart grid allows separate and professional customers to have principal roles in the system of electricity. Both independent consumers and authenticity of the system are getting advantages from active customer engagement. The modern grid must have dynamic protection system and provide combined and stable procedures for operation. Entire loads of power system are growing in the form of sensitive loads. For fulfilling the demands of responsive loads, the quality, which smart grid is delivering, must be enhanced. The loads could be more flexible for power delivery by getting design upgrades. Furthermore, the next feature of smart grid is the ability to unite markets of electricity and create an efficient system of electric power. Functioning, reliability, costs, and arranging are based on the structure of markets, which are easy to access. Appropriately, smart grid will brace electricity markets and restructure them. Finally, the management of assets through smart grid will allow getting high performance with minimum expenditures. For instance, advance diagnosis of the problem, as well as problem-fixing activities will be available throughout developed sensing system and dynamic communication system.

\subsection{Advantages and Disadvantages of Smart Grid}

Some of the main advantages and disadvantages of smart grid are described below: [9] [11] [16] [53].

\section{Advantages}

- Access to natural and sustainable sources of energy.

- Benefits for society due to depletion of waste from disruption of power.

- Growing amount of electric energy resources.

- Advanced protection of energy due to providing customers with data.

- The development in energy distributor sector will decrease the decrease the utility cost for the consumer. 
- Pressure on assets is decreasing by fulfilling the demand, which is minimizing failure likelihood.

- Capital funds rearrangement due to lessened loads of peak.

- Reduction of oil consumption due to decreasing ineffective generation requirements in top usage phases.

- Making available to shift from oil to electric energy for the transport system, which includes buses, cars, trains.

- Electric Greenhouse gas reduction due to stimulating machines with electricity and sustainable energy sources.

\section{Disadvantages}

- The critical issues are protection and seclusion.

- Hackers could crack some meter types.

- Hackers could:

o Gain access to thousands or millions of meters.

- Make the electricity demand to grow or to lessen.

- Despite to traditional grid, smart grid consists of multiple components.

- Diverse technical elements-the engines of power, integrators of system, programs, etc.

- The installation is very costly and requires a big budget.

\subsection{Comparison between Traditional Grid and Smart Grid}

Contemporary electric grid complexes are being described by expressive vocabulary, for example, "traditional" or "smart." According to Mohd et al. [66], smart grid mechanisms, as well as the allowance of consumption data in real-time amplify the effectiveness of production, transmission, and usage. The energy classes relationships start to change due to this productiveness enhancement. Smalley [67] states that the process of switching from stockpiled fuels (natural gas, oil, coal, nuclear) into sustainable and renewable systems is becoming agiler through means for linking end-users and energy services. Accordingly, the traditional energy grid is becoming insufficient, which is starting to be more visible. Decentralized and inefficacious value chain limits traditional grid's potency and productivity. In opposition to traditional grid, the structure and design of smart grid give superior control over energy distribution and usage. Furthermore, it provides instant feedback for energy consumption. Thus, the mechanism of smart grid enables higher effectiveness and less wastage of resources. Table 4 gives a quick image of the traditional and smart grid.

Makansi [68] describes traditional grid by using five classes of assets: Source, Generation, Transmission, Delivery, and Distribution. This categorization is highlighting the value chain. At the same time, it emphasizes decentralization mentioned above of value chain. Makansi's energy value chain portrait indicates significant elements, such as Source of energy, Generation, Transmission, Supplying, the ultimate user. Different energy storage types and excess with the dump-load form were added by the revised model, which is shown in Figure 11. 
Table 4. Traditional grid vs smart grid.

\begin{tabular}{cc}
\hline Traditional Grid & Smart Grid \\
\hline Fewer detectors & Fully equipped with detectors \\
Electromechanical devices & Computerized devices \\
Manual observing system & Automatic observing system \\
Centralized power generation system & Decentralized/Distributed power generation system \\
Manual healing system & Automatic healing system \\
One-way communication system & Two-way communication system \\
Breakdowns and dark & Robust and islanding system \\
Fewer options for customers & Many options for customers \\
Restricted system & Extensive system \\
Less control over grid & Good control over grid \\
\hline
\end{tabular}

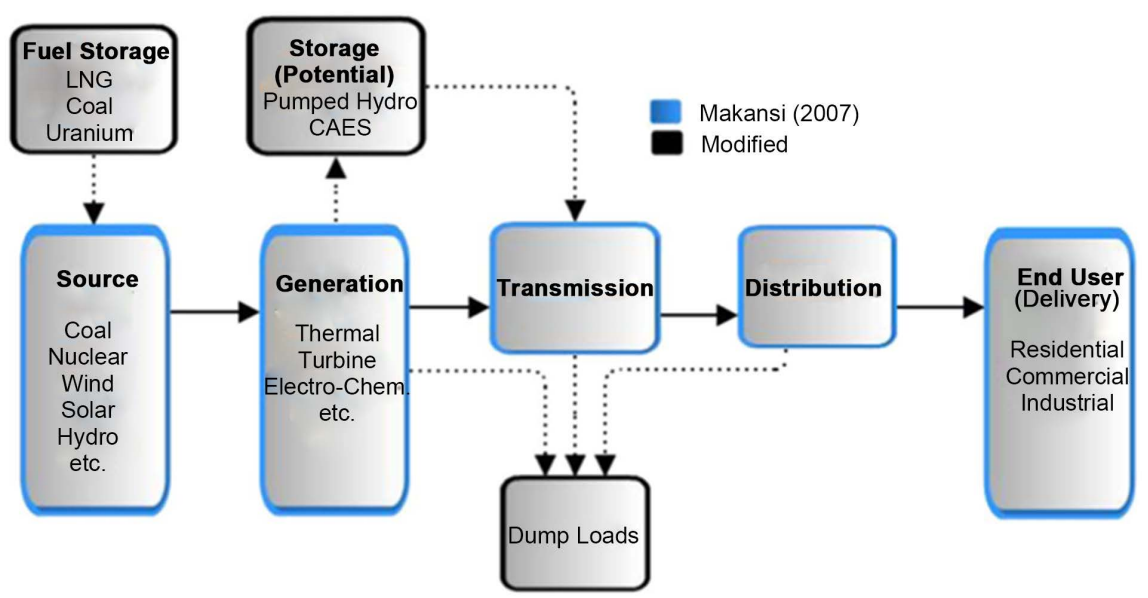

Figure 11. Traditional grid [69].

Data and the mono-directional flow of energy are the principal attributes of the grid mechanism.

The distribution is the only repeating circle around feedback. The reason is the surplus of discarded loads, which is redirecting the energy from the end user. The discarded loads cause more losses of revenue, which makes all costs and no income. Thus, grid operators have a stimulus for maximum reducing these incidents and keep the supposition of delivery, as well as high level of energy service quality. The technology, which collects usage information from end users and sends it to the operator of the grid, is used for describing smart grid. The collection and sending of data enhance the performance of grid, as well as informs users about real-time prices from generators. The information flow is described, which is another direction from the same assets category. The description is shown in Figure 12.

The dump loads are replaced with better information flow from electricity production. Smart grid mechanism illustration does these changes. Consequently, 


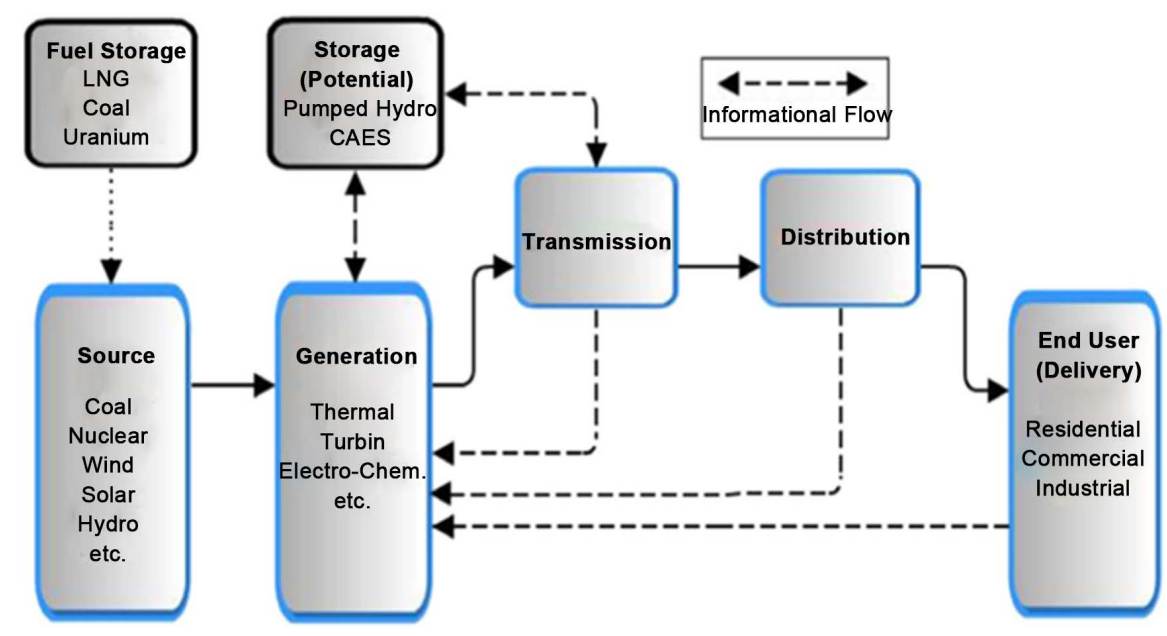

Figure 12. Smart grid [69].

it provides energy generator with demand based on real time. Moreover, the supply and customer needs are overlapping with each other, which is multiple times advantageous and efficient from the calculation of demand at any time. The limited suiting ability of feedback loop is the disadvantage of this system. The feedback loop suits only with energy generation. Thus, it makes the distribution less efficient because generators ramp up and down according to consumer demand, which fluctuates swiftly. Upgraded engines of energy generation are partly solving the problem. However, the level of the solution is not enough (i.e., residential use of solar energy). The differentiation between smart grid and traditional grid concentrates on increasing efficacy by improving the level of understanding. Makansi et al. [70] argue that more valuable information creates an opportunity for enhancing the operations. Meanwhile, consumer costs could be decreased by more accessible and balanced distribution system. In this value chain, the storage of energy has more additional position instead of central position (see Figure 12). Thus, it restricts energy storage service value, as well as makes administration of storage possession more complex.

\subsection{Future Challenges for Smart Grid}

Hoang [47] stated some of the prominent challenges for implementing smart grid:

Finance: From business-perspective it is efficient to have the ability to automate restoring, especially if it gives advantages to society. However, for investing in new technology, authorities will demand evidence, mainly if the technique depends on benefits for the community.

Assistance from Government: The industry sector does not have sufficient financial resources for funding new system installment. Therefore, it is necessary to get support from the government in the form of individual programs and activities to motivate new investments. Although the industry contains capital, which equals to $\$ 800$ billion, it experienced financial problems, which caused 
economic rankings' reduction.

Competent Apparatus: Older technologies are not well-suited with smart grid, and they cannot be reinstalled for suiting. Thus, the old equipment must be changed, which could cause obstacles regarding laws and controllers. Maintaining the old machinery more than its optimal service time decreases the spending of customers. At the same time, early exit of the apparatus could be a problem.

Technical Advancement Speed: 50 years ago, people predicted the solar gravel, chimney wind turbine and the fuel cell of an underground room. They described these technologies as inherent in future house design. This historical evolution should be reinforced.

Rules and Regulations: The providers of utilities often take into consideration new projects and plans of construction. The crossing state border of first circuit tie has always faced refusal. The government authorities who give the funds for the program are not ever getting advantages from the project. Thus, the utility providers will only invest in smart grid if the returns are high and sufficient.

Collaboration: The collaboration of 3000 various utilities is required for establishing critical circuit ties and spreading the information about integrating and implementing the concepts of smart grid.

\section{Discussion}

The primary objective of this discussion is to explore and exploit the sustainable and eco-friendly power management system. The term "distributed energy system" means a system in which electric energy generators are near to end-users. Moreover, distributed energy system contains the change of decision-making place, changes in control and possession of electricity distribution. In the future system of energy is going to be a combination of distributed and centralized sub-systems, which will operate simultaneously [28]. Multiple analysis of electric technologies and its mechanisms are focused on finding the special method for using centralized generation (CG), decentralized generation (DG) or localized generation (LG) to satisfy the increasing demand. As per Momoh et al. [31], distributed energy system is a useful choice, especially for a long term.

According to Association [23] report, the rapid change and growth have been noticed of electro-mechanical to electronic-based devices which have directly been affecting the requirement of energy and the grid operations. In this modern era, $92 \%$ of transport is fueled by petroleum. However, the immediate rise of electricity demand has been predicted in the transportation sector, as the concept of plug-in electric vehicles is rapidly increasing. The $18.6 \%$ annual growth rate of the electric vehicle is being predicted from 2013 to 2022 if this prediction of electric vehicle sale continues then the demand for electricity will remarkably be increased. Moreover, Tanaka [19] stated that the consumption of electricity is expected to grow by over $115 \%$ from 2007 to 2050.

On the other hand, it is difficult for a traditional grid with old technology to 
meet the rising demand for electricity. Zame et al. [70] added it has become more visible that traditional grid is an inadequate power distribution system. As per Hossain et al. [42] traditional grid depends on centralized power generation system which consumes lots of fossil fuels and emits greenhouse gases, that makes traditional grid ultimately a useless and environmentally extravagant system. Feisst et al. [24] comment that centralized power generation system has become a primary cause of emitting around $25 \%$ of global greenhouse gases. Furthermore, Banerjee et al. [22] explained that traditional grid cannot adapt the upcoming innovative technology, such as; power generation sources with low inertia, the demand for higher flexibility and the distributed power generation resources of rising diffusion. Therefore, Hossain et al. [42] stated that traditional grid is not suited for distributed, wind energy and renewable solar energy sources.

Nonetheless, the advancement of innovative technology has changed the scenario and played a significant role in transforming traditional grid into smart grid. Modern electrical technologies have empowered intelligent devices to interact with each other, measuring and evaluating the integrity and health of electric grid. Similarly, to prevent energy theft, eliminate the billing estimation system and automatically take meter reading [47]. Climate forecasting technology can accurately predict the changes in weather conditions which effects on power generation through renewable energy sources [9]. Furthermore, digitalized technology allows the grid to indicate the disturbance and faults in the grid. In case of any disruption, technology helps the system to restructure grids in affected areas and re-adjust rapidly with the newly assigned network topology which allows the system to reduce the severity of the disturbance and faults of the grid [51]. Finally, energy storage technologies have a high capability to integrate with renewable energy sources which help to mitigate the future demand of electricity [8] [52].

The latest studies reveal that a smart grid is fully equipped with agile, robust and more flexible techniques and technologies [16]. Power generation sources and grid operators can dynamically be optimized in a smart grid system; disturbances can rapidly be detected and mitigated, capable of protecting against cyber and physical risks [22]. According to Papavasiliou and Oren [57], nowadays the adoption of sustainable energy sources by smart grid system is becoming supreme and significant, which is gaining more attention of researchers. Atteya et al. [58] added that smart grid has more essential functions, besides sustainable energy unification and depository of energy in the distribution system. According to Vallee et al. [59], combining sustainable energy sources into smart grid is allowing to reduce greenhouse gases and decreasing the usage of fossil fuels and to save the cost, regarding constructing more centralized power generation units. Moreover, Banerjee et al. [22] stated that consumers are in-charge to manage the use of electricity, and finally, the smart grid can efficiently be integrated with renewable energy sources and decentralized power generation sys- 
tems which can respond the rising demand for electricity.

\section{Conclusion}

Finally, we have come to the point that decentralized and localized power generation systems are the better options for generating power, as both systems are closed to the end-users which save the cost of transmission and supply of electricity. Integration of renewable energy sources with decentralized and localized systems is possible which helps to provide clean and inexpensive energy without emitting greenhouse gases. Similarly, with the help of digitalized technology traditional grid can be transformed into smart grid which enables smart devices to interact with each other, measuring and evaluating the integrity and health of electric grid. Smart grid is a two-way communication system which is fully equipped with innovative technologies that can improve choices and awareness for the consumers, consistency in the performance of electric supply and enables utility providers and consumers to take independent decisions in delivering and receiving services. Moreover, energy storage technologies have a high capability to integrate with smart grid and renewable energy sources which help to store and distribute electricity according to the required need. The rise of electricity demand can be mitigated by installing smart meters, utilizing proper electric grid management techniques and time-based rates application. It encourages consumers to use electricity during off-peak hours which will save them from additional charges. Finally, smart grid is loaded with the core functionality of plug-in electric vehicles which has the complete capability to fulfill the demand of power for electric vehicles. Thus, the mechanism of smart grid allows higher effectiveness and less wastage of resources which enable it to achieve the rising demand for electricity. However, smart grid still faces some challenges such as; government support is required which is not easy in some cases; the initial massive investment needs to install the automated system; replacing obsolete equipment with new digitalized systems; and facing different rules and regulations imposed by individual governments.

\section{References}

[1] Mwasilu, F., et al. (2014) Electric Vehicles and Smart Grid Interaction: A Review on Vehicle to Grid and Renewable Energy Sources Integration. Renewable and Sustainable Energy Reviews, 34, 501-516. https://doi.org/10.1016/j.rser.2014.03.031

[2] Zakhidov, R. (2008) Central Asian Countries Energy System and Role of Renewable Energy Sources. Applied Solar Energy, 44, 218-223. https://doi.org/10.3103/S0003701X08030201

[3] Bergmann, A., Colombo, S. and Hanley, N. (2008) Rural versus Urban Preferences for Renewable Energy Developments. Ecological Economics, 65, 616-625. https://doi.org/10.1016/j.ecolecon.2007.08.011

[4] Kaundinya, D.P., Balachandra, P. and Ravindranath, N. (2009) Grid-Connected versus Stand-Alone Energy Systems for Decentralized Power-A Review of Literature. Renewable and Sustainable Energy Reviews, 13, 2041-2050. 
https://doi.org/10.1016/j.rser.2009.02.002

[5] Bhattacharyya, S.C. (2006) Energy Access Problem of the Poor in India: Is Rural Electrification a Remedy? Energy Policy, 34, 3387-3397.

https://doi.org/10.1016/j.enpol.2005.08.026

[6] Hiremath, R., et al. (2011) Implications of Decentralised Energy Planning for Rural India. Journal of Sustainable Energy \& Environment, 2, 31-40.

[7] Ravindranath, N.H. and Hall, D.O. (1995) Biomass, Energy and Environment: A Developing Country Perspective from India. Oxford University Press, Oxford.

[8] Prabhu, N.A., et al. (2016) Automatic Tap Changing in Transformers for Power Quality Enhancement in a Smart Grid Distribution System. International Conference on Electrical, Electronics, and Optimization Techniques (ICEEOT), Chennai, 3-5 March 2016, 4458-4463. https://doi.org/10.1109/ICEEOT.2016.7755562

[9] Li, Z. and Yao, T. (2010) Renewable Energy Basing on Smart Grid. 2010 6th International Conference on Wireless Communications Networking and Mobile Computing (WiCOM), Chengdu, 23-25 September 2010, 1-4. https://doi.org/10.1109/WICOM.2010.5600862

[10] Xiang, M., Bai, Q. and Liu, W. (2012) Self-Adjustable Trust-Based Energy Efficient Routing for Smart Grid Systems. 2012 IEEE/WIC/ACM International Conferences on Web Intelligence and Intelligent Agent Technology (WI-IAT), Macau, 4-7 December 2012, 378-382. https://doi.org/10.1109/WI-IAT.2012.89

[11] Mohani, S.S.H., et al. (2016) Smart Grid System. 2016 SAI Computing Conference (SAI), London, 13-15 July 2016, 1278-1285. https://doi.org/10.1109/SAI.2016.7556144

[12] Hiremath, R., Shikha, S. and Ravindranath, N. (2007) Decentralized Energy Planning; Modeling and Application-A Review. Renewable and Sustainable Energy Reviews, 11, 729-752. https://doi.org/10.1016/j.rser.2005.07.005

[13] Bevrani, H., Ghosh, A. and Ledwich, G. (2010) Renewable Energy Sources and Frequency Regulation: Survey and New Perspectives. IET Renewable Power Generation, 4, 438-457. https://doi.org/10.1049/iet-rpg.2009.0049

[14] Kim, Y.-J., et al. (2010) A Secure Decentralized Data-Centric Information Infrastructure for Smart Grid. IEEE Communications Magazine, 48, 58-65. https://doi.org/10.1109/MCOM.2010.5621968

[15] Odum, H.T. and Brown, M.T. (2007) Environment, Power and Society for the Twenty-First Century: The Hierarchy of Energy. Columbia University Press, Columbia.

[16] Valsamma, K. (2012) Smart Grid as a Desideratum in the Energy Landscape: Key Aspects and Challenges. 2012 IEEE International Conference on Engineering Education: Innovative Practices and Future Trends (AICERA), Kottayam, 19-21 July 2012, 1-6. https://doi.org/10.1109/AICERA.2012.6306708

[17] Rinkesh (2009) Renewable Energy Prons and Cons. https://www.conserve-energy-future.com/pros-and-cons-of-renewable-energy.php

[18] Randall, C.J. (2017) Renewable vs. Nonrenewable Energy Resources. https://classroom.synonym.com/renewable-vs-nonrenewable-energy-resources-309 81.html

[19] Tanaka, N. (2011) Technology Roadmap: Electric and Plug-In Hybrid Electric Vehicles. Technical Report, International Energy Agency.

[20] Taylor, P. (2010) Energy Technology Perspectives 2010. Scenarios \& Strategies to 2050 . 
[21] Kiefer, T.A. (2014) Ike: Disruptions to Utility Business Models. T\&D World Magazine.

[22] Banerjee, S., et al. (2011) Report on the First Quadrennial Technology Review. US Department of Energy.

[23] Association, S.E.I. (2014) Solar market Insight Report 2013 Year in Review. Technical Report, Solar Energy Industries Association.

[24] Feisst, C., Schlesinger, D. and Frye, W. (2008) Smart Grid: The Role of Electricity Infrastructure in Reducing Greenhouse Gas Emissions. Cisco Internet Business Solution Group (IBSG), San Jose, CA.

[25] Mohamed, M.A., et al. (2015) Energy Management and Renewable Energy Integration in Smart Grid System. 2015 IEEE International Conference on Smart Energy Grid Engineering (SEGE), Oshawa, 17-19 August 2015, 1-6. https://doi.org/10.1109/SEGE.2015.7324621

[26] Frye, W. (2008) Smart Grid Transforming the Electricity System to Meet Future Demand and Reduce Greenhouse Gas Emissions. Cisco Systems, San Jose, CA.

[27] Botterud, A., Ilic, M.D. and Wangensteen, I. (2005) Optimal Investments in Power Generation under Centralized and Decentralized Decision Making. IEEE Transactions on Power Systems, 20, 254-263. https://doi.org/10.1109/TPWRS.2004.841217

[28] Alanne, K. and Saari, A. (2006) Distributed Energy Generation and Sustainable Development. Renewable and Sustainable Energy Reviews, 10, 539-558. https://doi.org/10.1016/j.rser.2004.11.004

[29] Alanne, K. and Saari, A. (2004) Sustainable Small-Scale CHP Technologies for Buildings: The Basis for Multi-Perspective Decision-Making. Renewable and Sustainable Energy Reviews, 8, 401-431. https://doi.org/10.1016/j.rser.2003.12.005

[30] Conrad, K.L. and Affolter, R.H. (2011) Geochemical Database of Feed Coal and Coal Combustion Products (CCPs) from Five Power Plants in the United States. U.S. Geological Survey Data Series 635, Pamphlet, 19 p.

[31] Momoh, J.A., Meliopoulos, S. and Saint, R. (2012) Centralized and Distributed Generated Power Systems-A Comparison Approach. Future Grid Initiative White Paper, 1-10.

[32] Palensky, P. (2001) Distributed Reactive Energy Management. Ph.D. Thesis, Vienna University of Technology, Austria.

[33] Dunn, S. (2002) Hydrogen Futures: Toward a Sustainable Energy System. International Journal of Hydrogen Energy, 27, 235-264. https://doi.org/10.1016/S0360-3199(01)00131-8

[34] Conejo, A.J., et al. (2005) Locational Marginal Price Sensitivities. IEEE Transactions on Power Systems, 20, 2026-2033. https://doi.org/10.1109/TPWRS.2005.857918

[35] Martin, J. (2009) Distributed vs. Centralized Electricity Generation: Are We Witnessing a Change of Paradigm. An Introduction to Distributed Generation. HEC, Paris.

[36] Momoh, J. (2012) Smart Grid: Fundamentals of Design and Analysis. Vol. 63, John Wiley \& Sons, New Jersey. https://doi.org/10.1002/9781118156117

[37] Basso, T.S. and DeBlasio, R. (2004) IEEE 1547 Series of Standards: Interconnection Issues. IEEE Transactions on Power Electronics, 19, 1159-1162. https://doi.org/10.1109/TPEL.2004.834000

[38] Hadjsaid, N., Canard, J.-F. and Dumas, F. (1999) Dispersed Generation Impact on Distribution Networks. IEEE Computer Applications in Power, 12, 22-28. 
https://doi.org/10.1109/67.755642

[39] Asmus, P. (2010) Microgrids, Virtual Power Plants and Our Distributed Energy Future. The Electricity Journal, 23, 72-82. https://doi.org/10.1016/j.tej.2010.11.001

[40] Monaco, A. (2011) Edison's Pearl Street Station Recognized with Milestone. http://theinstitute.ieee.org/tech-history/technology-history/edisons-pearl-street-stat ion-recognized-with-milestone810

[41] Fang, X., et al. (2012) Smart Grid-The New and Improved Power Grid: A Survey. IEEE Communications Surveys \& Tutorials, 14, 944-980. https://doi.org/10.1109/SURV.2011.101911.00087

[42] Hossain, M.R., Oo, A.M. and Ali, A.S. (2013) Smart Grid. In: Ali, A.B.M.S., Ed., Smart Grids. Opportunities, Developments and Trends, Springer, London, 23-44. https://doi.org/10.1007/978-1-4471-5210-1_2

[43] Farhangi, H. (2010) The Path of the Smart Grid. IEEE Power and Energy Magazine, 8, 18-28. https://doi.org/10.1109/MPE.2009.934876

[44] Angelos, E.W.S., et al. (2011) Detection and Identification of Abnormalities in Customer Consumptions in Power Distribution Systems. IEEE Transactions on Power Delivery, 26, 2436-2442. https://doi.org/10.1109/TPWRD.2011.2161621

[45] Kang, C., Chen, Q. and Xia, Q. (2009) Prospects of Low-Carbon Electricity. Power System Technology, 33, 1-7.

[46] Kempener, R., Komor, P. and Hoke, A. (2013) Smart Grids and Renewables: A Guide for Effective Deployment. International Renewable Energy Agency (IRENA), IRENA Working Paper. https://www.irena.org/documentdownloads/publications/smart_grids.pdf

[47] Hoang, B. (2009) Smart Power Grids-Talking about a Revolution. IEEE Emerging Technology Portal, 2006-2012.

[48] Luan, W., Sharp, D. and Lancashire, S. (2010) Smart Grid Communication Network Capacity Planning for Power Utilities. 2010 IEEE PES Transmission and Distribution Conference and Exposition, New Orleans, 19-22 April 2010, 1-4.

[49] Ghosh, A., et al. (2005) Broadband Wireless Access with WiMax/802.16: Current Performance Benchmarks and Future Potential. IEEE Communications Magazine, 43, 129-136. https://doi.org/10.1109/MCOM.2005.1391513

[50] Deb, S., Bhowmik, P.K. and Paul, A. (2011) Remote Detection of Illegal Electricity Usage Employing Smart Energy Meter-A Current Based Technique. 2011 IEEE PES Innovative Smart Grid Technologies-India (ISGT India), Kollam, 1-3 December 2011, 391-395. https://doi.org/10.1109/ISET-India.2011.6145348

[51] Yang, J., Qian, A. and Da, X. (2010) Clean Energy Grid-Connected Technology Based on Smart Grid. Low Voltage Apparatus, 4, 213-218. https://doi:10.1016/j.egypro.2011.10.030

[52] Katiraei, F., et al. (2008) Microgrids Management. IEEE Power and Energy Magazine, 6, 54-65. https://doi.org/10.1109/MPE.2008.918702

[53] Forte, V.J. (2010) Smart Grid at National Grid. 2010 Innovative Smart Grid Technologies (ISGT), Gaithersburg, 19-21 January 2010, 1-4. https://doi.org/10.1109/ISGT.2010.5434729

[54] Chang, S., et al. (2014) A Beamforming Approach to Smart Grid Systems Based on Cloud Cognitive Radio. IEEE Systems Journal, 8, 461-470. https://doi.org/10.1109/JSYST.2013.2260693

[55] Horowitz, S.H., Phadke, A.G. and Renz, B.A. (2010) The Future of Power Transmission. IEEE Power and Energy Magazine, 8, 34-40. 
https://doi.org/10.1109/MPE.2009.935554

[56] Yin, S.-G., Zhang, Y. and Bai, K.-M. (2009) A Smart Power Utilization System Based on Real-Time Electricity Prices. Power System Technology, 19, 11-16.

[57] Papavasiliou, A. and Oren, S.S. (2014) Large-Scale Integration of Deferrable Demand and Renewable Energy Sources. IEEE Transactions on Power Systems, 29, 489-499. https://doi.org/10.1109/TPWRS.2013.2238644

[58] Atteya, I., et al. (2016) Distribution Network Reconfiguration in Smart Grid System Using Modified Particle Swarm Optimization. 2016 IEEE International Conference on Renewable Energy Research and Applications (ICRERA), Birmingham, 20-23 November 2016, 305-313. https://doi.org/10.1109/ICRERA.2016.7884556

[59] Vallee, F., Lobry, J. and Deblecker, O. (2008) System Reliability Assessment Method for Wind Power Integration. IEEE Transactions on Power Systems, 23, 1288-1297. https://doi.org/10.1109/TPWRS.2008.926090

[60] Gaviano, A., Weber, K. and Dirmeier, C. (2012) Challenges and Integration of PV and Wind Energy Facilities from a Smart Grid Point of View. Energy Procedia, 25, 118-125. https://doi.org/10.1016/j.egypro.2012.07.016

[61] Shahraeini, M., Javidi, M.H. and Ghazizadeh, M.S. (2011) Comparison between Communication Infrastructures of Centralized and Decentralized Wide Area Measurement Systems. IEEE Transactions on Smart Grid, 2, 206-211. https://doi.org/10.1109/TSG.2010.2091431

[62] Liserre, M., Sauter, T. and Hung, J.Y. (2010) Future Energy Systems: Integrating Renewable Energy Sources into the Smart Power Grid through Industrial Electronics. IEEE Industrial Electronics Magazine, 4, 18-37. https://doi.org/10.1109/MIE.2010.935861

[63] Miao, X., et al. (2009) Information Communication System Supporting Smart Grid. Power System Technology, 33, 8-13.

[64] Yu, Y. and Luan, W. (2009) Power System and Clean Energy. Smart Grid, 25, 7-11.

[65] Xie, K., et al. (2008) The Vision of Future Smart Grid. Electric Power, 6, 008.

[66] Mohd, A., et al. (2008) Challenges in Integrating Distributed Energy Storage Systems into Future Smart Grid. IEEE International Symposium on Industrial Electronics, Cambridge, 30 June-2 July 2008, 1627-1632.

[67] Smalley, R.E. (2005) Future Global Energy Prosperity: The Terawatt Challenge. MRS Bulletin, 30, 412-417. https://doi.org/10.1557/mrs2005.124

[68] Makansi, J. (2007) Lights Out: The Electricity Crisis, the Global Economy, and What It Means to You. John Wiley \& Sons, London.

[69] Zame, K.K., et al. (2017) Smart Grid and Energy Storage: Policy Recommendations. Renewable and Sustainable Energy Reviews. https://fardapaper.ir/mohavaha/uploads/2017/09/323226156459456152459.pdf

[70] Makansi, J. and Abboud, J. (2002) Energy Storage. Energy Storage Council White Paper. 